\title{
Injection Site Lichenoid Dermatitis Following Pneumococcal Vaccination: Report and Review of Cutaneous Conditions Occurring at Vaccination Sites
}

Philip R. Cohen

Received: February 8, 2016/Published online: March 17, 2016

(C) The Author(s) 2016. This article is published with open access at Springerlink.com

\begin{abstract}
Background: Cutaneous dermatoses and malignancies have occurred at the sites of vaccines.

Purpose: To describe a man who developed a lichenoid dermatitis at the pneumococcal vaccine injection site and to review cutaneous dermatoses and malignancies occurring at vaccination sites.
\end{abstract}

Methods: PubMed was used to search the following terms, separately and in combination: adverse, condition, cutaneous, dermatosis, dermatitis, injection, PCV13, pneumococcal, pneumonia, prevnar, reaction, skin, site, vaccination, and vaccine. All papers were reviewed, and relevant manuscripts, along with their reference citations, were evaluated.

Enhanced content To view enhance content for this article go to www.medengine.com/Redeem/ B944F0606A3DC325.

P. R. Cohen $(\square)$

Department of Dermatology, University of

California San Diego, San Diego, CA, USA

e-mail: mitehead@gmail.com
Results: Several vaccines-including bacillus Calmette-Guerin, hepatitis B, influenza, leishmaniasis, meningitis, pneumococcal, smallpox, tetanus (alone and in combination with diphtheria, pertussis, polio, Haemophilus influenza type B or plague and yellow fever), and varicella-zoster-have been associated with post-vaccination site reactions. A 70-year-old male developed a lichenoid dermatitis that occurred at the pneumococcal vaccine injection site within 2 weeks after PCV13 vaccination; the erythematous nodule resolved spontaneously within 9 weeks following immunization.

Conclusions: Dermatoses at the injection sites of vaccines can be granulomatous, immunity-related conditions, infections, lichenoid, neutrophilic, or pseudolymphomatous. Basal cell carcinoma and squamous cell carcinoma are the most common vaccination site-associated malignancies; however, melanoma and sarcomas (dermatofibrosarcoma protuberans, fibrosarcoma, and malignant fibrous histiocytoma) are also smallpox vaccine-related site neoplasms. A cutaneous immunocompromised district that is created by vaccine-induced local immunologic changes is hypothesized to be the pathogenesis of vaccination site reactions. 
Keywords: Adverse reaction; Cutaneous; Dermatosis; Dermatitis; Injection; PCV13; Pneumococcal; Pneumonia; Prevnar; Vaccine

\section{INTRODUCTION}

The pneumococcal polysaccharide conjugated vaccine (13-valent, adsorbed; PCV13, Prevnar 13 ) is approved in adults $\geq 50$ years for the prevention of pneumonia in the USA [1-3]. Lichenoid dermatitis describes a skin condition that is microscopically characterized by band-like lymphocytic inflammation with alteration of the epidermal basal layer. The case of a man who developed a lichenoid dermatitis at the site of immunization within 2 weeks after receiving the PCV13 vaccine is described, and cutaneous conditions occurring at vaccinations sites are reviewed.

\section{CASE REPORT}

A 70-year-old male presented for evaluation of a new, asymptomatic, red and scaly lesion on his left arm. He had received a vaccination, pneumococcal polysaccharide conjugated vaccine (13-valent, adsorbed; PCV13, Prevnar 13) at the site 5 weeks earlier. Within 2 weeks after being immunized, he noticed the skin lesion. He had been vaccinated with the pneumococcal polysaccharide vaccine (PPSV23, Pneumovax) 6 years earlier.

Cutaneous examination showed a $12 \times 5$-mm linear, focally crusted, erythematous nodule on the deltoid area of his left arm (Fig. 1); the location corresponded to the PCV13 injection site.

Microscopic evaluation of a 3-mm punch biopsy showed orthokeratosis, acanthosis, and a prominent granular layer. Dyskeratotic keratinocytes were present in the epidermis,

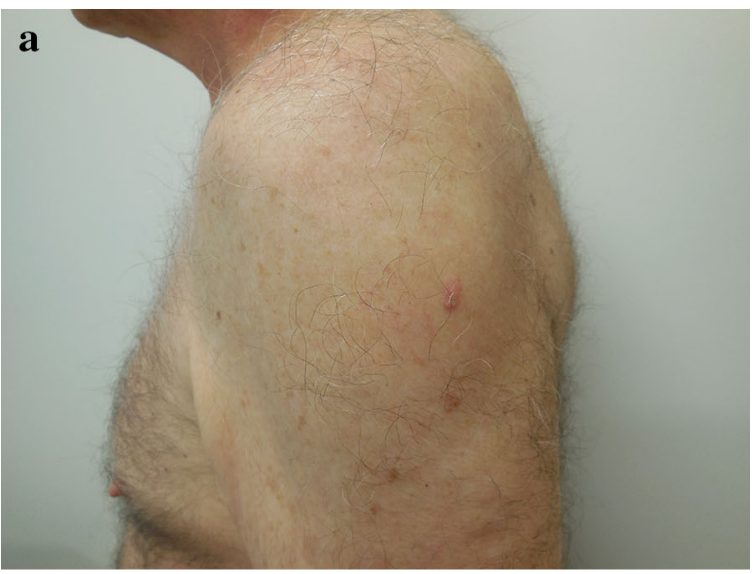

b

Fig. 1 Distant (a) and closer (b) views of the pneumococcal vaccination site on the left deltoid area show a $12 \times 5 \mathrm{~mm}$ linear, focally crusted, erythematous nodule

and there was a vacuolar change of the basal cells at the dermoepidermal interface. In the upper dermis there was dense, band-like infiltration of lymphocytes with occasional exocytosis of the inflammatory cells into the overlying spongiotic epidermis (Fig. 2).

Correlation of the history, clinical morphology, and pathologic changes established the diagnosis of a lichenoid dermatitis occurring at the vaccination site of the PCV13 vaccine. The residual dermatosis resolved spontaneously within 4 weeks after the biopsy, corresponding to 9 weeks after immunization. Follow-up examination showed normal-appearing skin at the vaccination site. 


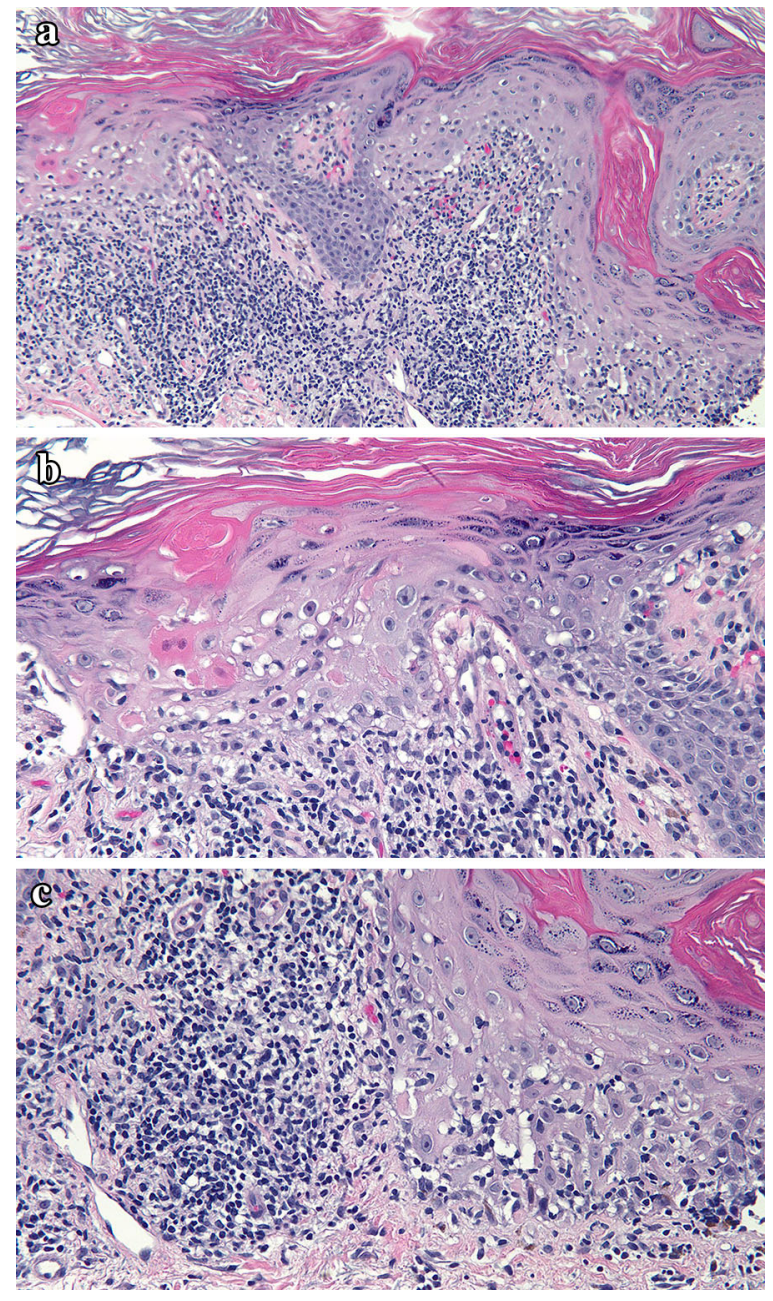

Fig. 2 Distant (a) and closer (b, c) views of the skin biopsy show orthokeratosis, acanthosis, and a prominent granular layer (a, b). There is mild spongiosis (c), dyskeratotic keratinocytes (a, b), and vacuolar change of the basal cells at the dermoepidermal interface $(\mathbf{a}-\mathbf{c})$. Lymphocytes are present in a dense, band-like infiltrate in the upper dermis (a, b), and there is exocytosis of the inflammatory cells into the overlying epidermis (a, c) (hematoxylin and eosin, $\mathbf{a}=\times 10 ; \mathbf{b}=\times 20 ; \mathbf{c}=\times 20$ )

Informed consent was obtained from the patient for being included in the study.

\section{DISCUSSION}

The 7-valent pneumococcal conjugated vaccine (PCV, known by the trade name Prevnar) was licensed by the Food and Drug Administration (FDA) on 17 February 2000 [4]. Subsequently, vaccines toward 13 and 23 serotypes of Streptococcus pneumonia were developed. PCV13 consists of 13 serotype-specific polysaccharides of $S$. pneumoniae $(1,3,4,5,6 \mathrm{~A}, 7 \mathrm{~F}, 9 \mathrm{~V}, 14,18 \mathrm{C}$, $19 \mathrm{~A}, 19 \mathrm{~F}$, and 23F) conjugated individually to non-toxic diphtheria $\mathrm{CRD}_{197}$ carrier protein and adsorbed on aluminum phosphate. The US Advisory Committee on Immunization Practices (ACIP) has recommended PCV13 [in series with 23-valent pneumococcal polysaccharide vaccine (PPVS23, Pneumovax)] for all adults aged $\geq 65$ years. A single $0.5-\mathrm{mm}$ dose is given as an intramuscular injection in the deltoid muscle [3, 5-9].

PCV13 has been associated with not only systemic adverse events, but also local reactions of only mild or moderate severity; no vaccine-related serious events were reported [8]. Systemic adverse events associated with the vaccine include arm movement limitation, arthralgia, chills, decreased appetite, diarrhea, fatigue, fever, headache, myalgia, rash, and vomiting. In general, these reactions were less common in older persons than in younger individuals $[1-3,7]$.

Skin and subcutaneous tissue disorders accounted for $20 \%$ of total adverse events following immunization in a 10-year retrospective analysis of spontaneous reports following pediatric immunizations [10]. Cutaneous reactions to vaccinations can be nonspecific or related to the live attenuated virus; they can also be localized to the injection site or associated with generalized hypersensitivity reactions [11]. Investigators have proposed not only the case definition, but also the guidelines for collection, analysis, and presentation of immunization safety data for local reactions at or near vaccine injection sites [12]. 
Table 1 Pneumococcal vaccination site reactions

Injection site reactions:

Abscess or cellulitis $^{\mathrm{a}}[4]$

Erythema, pain, and swelling ${ }^{\mathrm{a}}[1-4]$

Itching granuloma ${ }^{\mathrm{b}}[14]$

Keratoacanthoma [15]

Lichenoid dermatitis [current report]

Sweet's syndrome ${ }^{c}[16]$

Delayed maturation of the antibody response to the pneumococcal vaccine was observed in children with atopic eczema who received Pneumovax II (Pasteur Merieux MSD Ltd., Maidenhead, UK). Specifically, in comparison to controls (of whom 57\% responded to the vaccine), only $17 \%$ of children with atopic dermatitis aged 3-8 years responded to Pneumovax II [13]

a Injection site reactions following vaccination with the 7-valent pneumococcal conjugated vaccine (PCV, trade name Prevnar, Wyeth Pharmaceuticals, Philadelphia, PA) were described in $54 \%$ of 4154 reports of events after immunization; 8 serious reports described abscess or cellulitis [4]

b Itching granuloma occurred in 38 of 4758 children $(0.83 \%)$ who received Infanrix or Pentavac alone or concomitant with pneumococcal conjugate (Prevnar). Accompanying clinical features at the injection site in some of the patients also included bluish discoloration, dermatitis, excoriations, hyperpigmentation, hypertrichosis, and scar. Contact allergy to aluminum was verified in 29 of the 34 children (85\%) who were evaluated by epicutaneous testing with aluminum

c Sweet's syndrome was also triggered by pneumococcal vaccination that had taken place 15 days earlier; however, the patient did not have any lesions at the injection site [17]

Cutaneous reactions at the site of PCV13 are summarized in Table 1 [1-4, 13-17]. Local reactions such as erythema, pain and swelling at the injection site were common; they were more severe in younger aged patients than in older individuals [1-3]. The reported patient is the first individual with a lichenoid dermatitis that appeared at the vaccine injection site within 2 weeks and spontaneously resolved in 9 weeks.
Table 2 Bacillus Calmette-Guerin (BCG) vaccination site reactions

Abscess [18-20]

Basal cell carcinoma [21]

Blistering [18, 19, 22]

Epithelial cysts [18, 19, 22]

Erythema $[18,19,22]$

Erythematous nodule (necrotizing granulomatous reaction) [22]

Fixed drug eruption [23]

Foreign body granuloma (non-necrotizing) [24]

Granuloma annulare [25, 26]

Granuloma (delayed) [19]

Isotopic response to patch testing [27]

Keloid [7, 19, 22, 28]

Lupus vulgaris (cutaneous tuberculosis) [29-33]

Lymphadenopathy (suppurative) [18-20, 34]

Papular tuberculids [20]

Pilomatricoma [35]

Psoriasis [36]

Sarcoidosis (juvenile) [37]

Squamous cell carcinoma $[33,38]$

Sweet's syndrome $[39,40]$

Tufted angioma [41]

Ulceration $[18,19,22]$

Ulceration during Kawasaki disease [42, 43]

Vasculitis (ulcerating) [44]

Cutaneous dermatoses and malignancies have occurred at the sites of other vaccines, including Bacillus Calmette-Guerin (Table 2) [18-44], hepatitis B (Table 3) [28, 45-53], smallpox (Table 4) [28, 54-79], tetanus (Table 5) $[14,80-86]$, and others (Table 6) [36, 51, 55, 73, 87-97]. Granuloma annulare is one of the more common skin conditions to subsequently occur 
Table 3 Hepatitis B vaccination site reactions

Churg-Strauss vasculitis [45]

Granuloma annulare [46]

Injection site reactions: edema, erythema, induration, and pain [47]

Keloid [28]

Mastocytoma [48]

Necrobiotic granuloma [49]

Nodules [50]

Papulonodular lichenoid ${ }^{a}$ and pseudolymphomatous reaction [47]

Subcutaneous nodule (cutaneous B-cell pseudolymphoma) [51]

${ }^{a}$ Generalized lichenoid reactions and lichen planus have occurred following hepatitis $B$ vaccination; however, the initial or individual lesion was not localized to the site of vaccination $[52,53]$

at the site of an immunization [25, 26, 46, 98, 99]. The most frequently observed vaccination site-associated malignancy is basal cell carcinoma [33, 38, 55-57, 73], followed by squamous cell carcinoma $[33,38,54,55,57$, 73]. However, the prevalence of melanoma [55, 57, 73] and sarcomas (dermatofibrosarcoma protuberans, fibrosarcoma, and malignant fibrous histiocytoma) [55, 57, 60-62, 72] in smallpox vaccination scars-as compared to the scars of other vaccines-is greater than expected and may be secondary to a unique characteristic of the vaccine (Table 7) $[15,33,38,54-57,60-62$, 69, 72, 73, 86, 90, 94-96].

Vaccine-associated adverse effects at the site of injection may, in part, be secondary to the the polysaccharides and bases it contains. However, there are no predictors as to which individuals will develop these side effects. It remains to be determined why some patients experienced inflammatory dermatoses whereas others developed neoplasms at their vaccination sites.
Table 4 Smallpox vaccination site reactions

Allergic contact dermatitis [54]

Basal cell carcinoma [55-57]

Dermatitis, chronic [54]

Dermatofibroma $[58,59]$

Dermatofibrosarcoma protuberans $[55,57,60,61]$

Fibrosarcoma [62]

Herpes simplex virus infection [63]

Inflammatory reaction, localized ${ }^{\mathrm{a}}$ [64]

Keloid (exaggerated scarring) [28, 55, 64-68]

Keratoacanthoma [69]

Lupus erythematosus (discoid) [70, 71]

Malignant fibrohistiocytoma $[55,57,72]$

Melanoma [55, 57, 73]

Myxedematous infiltration, diffuse (Graves' disease) [74]

Nevus sebaceous [75]

Pigmentation $[76,77]$

Post scab lesions ${ }^{\mathrm{b}}[54]$

Progressive vaccinia ${ }^{c}[78]$

Pyogenic infections [78]

Robust take ${ }^{\mathrm{d}}$ [78]

Scar response $(\text { normal) })^{\mathrm{e}}[57,78]$

Squamous cell carcinoma $[54,55,57]$

Sweet's syndrome [79]

a A localized inflammatory reaction at the vaccination site heals with a slightly depressed smooth scar that slowly fades and rarely requires treatment

b The morphology of the lesion includes (in order of frequency) erythema, papule, pustule, vesicle, induration, and scab; all except induration and scab may recur in some patients after the original lesions spontaneously resolve. Lesion biopsies (in 4 patients) showed allergic contact dermatitis (2), chronic dermatitis (1), and squamous cell carcinoma (1)

c Progressive vaccinia is also referred to as disseminated vaccinia, prolonged vaccinia, vaccinia gangrenosum, and vaccinia necrosum. The vaccination site does not heal; there is painless progressive necrosis that develops into an ulcerative lesion. Additional lesions may or may not appear at distant sites, such as skin, bone, and viscera

$\mathrm{d}$ Robust take is a non-progressive cutaneous reaction at the vaccination site of $>7.5 \mathrm{~cm}$ with swelling, warmth, and joint pain; the symptoms peak at $8-10$ days post vaccination, and there is improvement within $24-72 \mathrm{~h}$

e The normal scar response at the site of vaccination is the following sequence: papule at day 4 post vaccination, pustule at day 7-14, and scab at day 21 
Table 5 Tetanus vaccination site reactions

Tetanus vaccine

Angiolymphoid hyperplasia with eosinophils [80]

Indurated erythematous plaque (cutaneous B-cell pseudolymphoma) [51]

Granuloma annulare [81]

Tetanus and diphtheria vaccine

Granuloma annulare [26]

Tetanus, diphtheria, and pertussis vaccine

Abscess (Mycobacterium tuberculosis) [82]

Deep reactive nodular infiltrates of mixed inflammation [83]

Necrotizing granuloma [83]

Tetanus, diphtheria, pertussis, and polio vaccine

Abscess (Mycobacterium chelonei) [84]

Tetanus, diphtheria, pertussis, polio, and Haemophilus

influenza type $B$ vaccine

Itching granuloma ${ }^{a}[14]$

Subcutaneous nodule (sterile abscess) ${ }^{\mathrm{b}}[85]$

Tetanus, plague, and yellow fever vaccine

Dermatofibrosarcoma protuberans [86]

${ }^{a}$ Itching granuloma occurred in 38 of 4758 children $(0.83 \%)$ who received Infanrix or Pentavac alone or concomitant with pneumococcal conjugate (Prevnar). Accompanying clinical features at the injection site in some of the patients also included bluish discoloration, dermatitis, excoriations, hyperpigmentation, hypertrichosis, and scar. Contact allergy to aluminum was verified in 29 of the 34 children (85\%) who were evaluated by epicutaneous testing with aluminum

b The patient received the Pentacel vaccine

Ruocco et al. proposed the immunocompromised district as a unifying concept for the development of skin disorders and cancer at lymphoedematous, herpes-infected, and otherwise damaged cutaneous sites in 2009 [99]. The concept has subsequently been expanded with regards to not only the factors responsible for the regional
Table 6 Other vaccination site reactions

Early summer meningitis

Subcutaneous nodule (cutaneous B-cell pseudolymphoma) [51]

Influenza vaccine

Psoriasis [36]

Sweet's syndrome [87-89]

Leishmaniasis vaccine

Dermatofibrosarcoma protuberans [90]

Varicella-zoster virus vaccine

Burning [91]

Erythema [91]

Pruritus [91]

Subcutaneous nodule (pseudolymphoma) [92]

Zosteriform eruption [93]

Vaccine not specified

Basal cell carcinoma $[55,73]$

Dermatofibrosarcoma protuberans ${ }^{\mathrm{a}}[55,94,95]$

Lentigo maligna [96]

Lichen sclerosus et atrophicus [97]

Melanoma [55]

Squamous cell carcinoma $[55,73]$

a Includes pigmented dermatofibrosarcoma also referred to as Bednar tumor $[55,94]$

immune dysregulation (which also include burns, ionizing and ultraviolet radiation, neurologic disorders such as paralytic stroke and poliomyelitis, tattooing, and trauma such as amputation), but also the skin diseases arising in the affected sites (such as granulomatous reactions, immunity-related disorders, infections, and tumors) [100-102]. The occurrence of cutaneous dermatoses or skin cancers at vaccination sites is another example of an immunocompromised cutaneous district that has been created by local immunologic changes induced by the vaccine. 
Table 7 Cancers at vaccination sites

Basal cell carcinoma

Bacillus Calmette-Guerin vaccine [33, 38]

Smallpox vaccine [55-57]

Not specified [55, 72]

Dermatofibrosarcoma protuberans ${ }^{a}$

Leishmaniasis immunization [90]

Smallpox vaccine $[55,57,60,61]$

Tetanus, plague, and yellow fever vaccines [86]

Travel immunization [94]

Not specified [55, 95]

Fibrosarcoma

Smallpox vaccine $[57,62]$

Keratoacanthoma

Pneumococcal vaccine [15]

Smallpox vaccine [69]

Malignant fibrous histiocytoma

Smallpox vaccine $[55,57,72]$

Melanoma

Smallpox vaccine $[55,57,73]$

Not specified $[55,96]$

Squamous cell carcinoma

Bacillus Calmette-Guerin vaccine [33, 38]

Smallpox vaccine $[54,55,57]$

Not specified $[55,73]$

a These also include pigmented dermatofibrosarcoma protuberans (Bednar tumors) [55, 94]

\section{CONCLUSION}

Vaccination site reactions have been observed following immunization with several vaccines including Bacillus Calmette-Guerin, hepatitis B, influenza, leishmaniasis, meningitis, pneumococcal, smallpox, tetanus (alone and in combination with diphtheria, pertussis, polio, Haemophilus influenza type B or plague and yellow fever), and varicella-zoster. The reactions at the vaccine injection sites are either cutaneous dermatoses or neoplasms. In this report, a man is described who developed a lichenoid dermatitis that occurred at the pneumococcal vaccine injection site within 2 weeks after PCV13 vaccination; the erythematous nodule resolved spontaneously within 9 weeks following immunization. Dermatoses at the injection sites of vaccines can be granulomatous, immunity-related conditions, infections, lichenoid, neutrophilic, or pseudolymphomatous. Vaccination site-associated malignancies most commonly are basal cell carcinoma or squamous cell carcinoma; however, smallpox vaccine-related site neoplasms also include melanoma and sarcomas (dermatofibrosarcoma protuberans, fibrosarcoma, and malignant fibrous histiocytoma). The pathogenesis of vaccination site reactions is hypothesized to be the result of a cutaneous immunocompromised district created by vaccine-induced local immunologic changes.

\section{ACKNOWLEDGMENTS}

No funding or sponsorship was received for this study or publication of this article.

All named authors meet the International Committee of Medical Journal Editors (ICMJE) criteria for authorship for this manuscript, take responsibility for the integrity of the work as a whole, and have given final approval for the version to be published. 
Disclosures. Philip R. Cohen, MD, has nothing to disclose.

\section{Compliance with Ethics}

Guidelines. Informed consent was obtained from the patient for being included in the study.

Open Access. This article is distributed under the terms of the Creative Commons Attribution-NonCommercial 4.0 International License (http://creativecommons.org/licenses/ by-nc/4.0/), which permits any noncommercial use, distribution, and reproduction in any medium, provided you give appropriate credit to the original author(s) and the source, provide a link to the Creative Commons license, and indicate if changes were made.

\section{REFERENCES}

1. Food and Drug Administration. Prevnar 13 label. http://www.fda.gov/downloads/BiologicsBlood Vaccines/Vaccines/ApprovedProducts/UCM20 1669.pdf. Accessed Jan 1, 2016.

2. Sanford M. Pneumococcal polysaccharide conjugate vaccine (13-valent, adsorbed) in older adults. Drugs. 2012;72:1243-55.

3. Plosker GL. 13-Valent pneumococcal conjugate vaccine: a review of its use in adults. Drugs. 2015;75:1535-46.

4. Wise RP, Iskander J, Pratt RD, Campbell S, Ball R, Pless RP, Braun MM. Postlicensure safety surveillance for 7-valent pneumococcal conjugate vaccine. JAMA. 2004;292:1702-10.

5. Gruber WC, Scott DA, Emini EA. Development and clinical evaluation of Prevnar 13, a 13-valent pneumocococcal CRM197 conjugate vaccine. Ann NY Acad Sci. 2012;1263:15-26.

6. Weinberger DM, Shapiro ED. Pneumococcal conjugate vaccines for adults. Reasons for optimism and for caution. Hum Vaccin Immunother. 2014;10:1334-6.

7. Sucher AJ, Chahine EB, Nelson M, Sucher BJ. Prevnar 13, the new 13-valent pneumococcal conjugate vaccine. Ann Pharmacother. 2011;45:1516-24.

8. Bonten MJM, Huijts SM, Bolkenbaas M, Webber C, Patterson S, Gault S, van Werkhoven $\mathrm{CH}$, van Deursen AMM, Sanders EAM, Verheij TJM, Patton M, McDonough A, Moradoghli-Haftvani A, Smith $\mathrm{H}$, Mellelieu T, Pride MW, Crowther G, Schmoele-Thoma B, Scott DA, Jansen KU, Lobatto R, Oosterman B, Visser N, Caspers E, Smorenburg A, Emini EA, Gruber WC, Grobbe DE. Polysaccharide conjugate vaccine against pneumococcal pneumonia in adults. $\mathrm{N}$ Engl $\mathrm{J}$ Med. 2015;372:1114-25.

9. Tomczyk S, Bennett NM, Stoecker C, Gierke R, Moore MR, Whitney CG, Hadler S, Pilishvili T. Centers for disease control and prevention (CDC): use of 13-valent pneumococcal conjugate vaccine and 23-valent pneumococcal polysaccharide vaccine among adults aged $\geq 65$ years: recommendations of the Advisory Committee on Immunization Practices (ACIP). MMWR Morb Mortal Wkly Rep. 2014;63:822-6.

10. Aagaard L, Hansen EW, Hansen EH. Adverse events following immunization in children: retrospective analysis of spontaneous reports over a decade. Eur J Clin Pharmacol. 2011;67:283-8.

11. Rosenblatt AE, Stein SL. Cutaneous reactions to vaccinations. Clin Dermatol. 2015;33:327-32.

12. Gidudu J, Kohl KS, Halperin S, Hammer SJ, Heath PT, Hennig R, Hoet B, Rothstein E, Schuind A, Varricchio F, Walop W, The Brighton Collaboration Local Reactions Working Group for A Local Reaction at or near Injection Site. A local reaction at or near injection site: case definition and guidelines for collection, analysis, and presentation of immunization safety data. Vaccine. 2008;26:6800-13.

13. Arkwright PD, Patel L, Moran A, Haeney MR, Ewing CI, David TJ. Atopic eczema is associated with delayed maturation of the antibody response to pneumococcal vaccine. Clin Exp Immunol. 2000;122:16-9.

14. Bergfors E, Hermansson G, Kranandeer UN, Falk L, Valter L, Trollfors B. How common are long-lasting, intensely itching vaccination granulomas and contact allergy to aluminium induced by currently used pediatric vaccines? A prospective cohort study. Eur J Pediatr. 2014;173:1297-307.

15. Bart RS, Lagin S. Keratoacanthoma following pneumococcal vaccination: a case report. J Dermatol Surg Oncol. 1983;9:381-2. 
16. Maddox PR, Motley RJ. Sweet's syndrome: a severe complication of pneumococcal vaccination following emergency splenectomy. Br J Surg. 1990;77:809-10.

17. Pedrosa AF, Morais P, Nogueira A, Pardal J, Azevedo F. Sweet's syndrome triggered by pneumococcal vaccination. Cutan Ocul Toxicol. 2013;32:260-1.

18. Grange JM. Complications of bacilli Calmette-Guerin (BCG) vaccination and immunotherapy and their management. Commun Dis Public Health. 1998;1(2):84-8.

19. Bellet JS, Prose NS. Skin complications of bacillus Calmette-Guerin immunization. Curr Opin Infect Dis. 2005;18:97-100.

20. Figueiredo A, Poiares-Baptista A, Branco M, Carmona da Mota H. Papular tuberculids post-BCG vaccination. Int J Dermatol. 1987;26:291-4.

21. Kluger N, Monthieu JY, Guillot B. Basal cell carcinoma arising in a bacilli Calmette-Guerin vaccination scar. Cutis. 2012;89:137-9.

22. Keijsers RRMC, Bovenschen J, Seyger MMB. Cutaneous complication after BCG vaccination: case report and review of the literature. J Dermatol Treat. 2011;22:315-8.

23. Kanwar AJ, Kaur S, Nanda A, Sharma R. Fixed drug eruption at the site of BCG vaccination. Pediatr Dermatol. 1988;5:289.

24. Chiu YK, Huang CC, Jeng J, Shica J, Chen WJ. Foreign body granuloma caused by monosodium glutamate after BCG vaccination. J Am Acad Dermatol. 2006;55(2 Suppl):S1-5.

25. Houcke-Bruge C, Delaporte E, Catteau B, Martin De Lassalle E, Piette F. Granuloma annulare following BCG vaccination. Ann Dermatol Venereol. 2001;128:541-4.

26. Nomiyama T, Takenaka H, Kishimoto S, Katoh N. Granuloma annulare-like reaction to the bacillus Calmette-Guerin vaccination. Australasian J Dermatol. 2015;54:e4-7.

27. Bell HK, King CM. An isotopic response to patch testing. Contact Dermatitis. 2003;49:171-2.

28. Coop CA, Schaefer SM, England RW. Extensive keloid formation and progression after each vaccination. Hum Vaccin. 2007;3(4):127-9.

29. Izumi AK, Matsunaga J. BCG vaccine-induced lupus vulgaris. Arch Dermatol. 1982;118:171-2.
30. Singal A, Sonthalia S, Pandhi D. Ulcerated lupus vulgaris at the site of Bacille Calmette-Guerin vaccination. Pediatric Dermatol. 2013;30:147-8.

31. Attia E. BCG vaccine-induced lupus vulgaris. Eur J Dermatol. 2007;17:547-8.

32. Farsinejad K, Daneshpazhooh M, Sairafi $H$, Barzegar M, Mortazavizadeh M. Lupus vulgaris at the site of BCG vaccination: report of three cases. Clin Exp Dermatol. 2009;34:167-9.

33. Thakur BK, Verma S. BCG-induced lupus vulgaris complicated by squamous cell carcinoma in a 7-year-old child. Int J Dermatol. 2011;50:542-5.

34. Lotte A, Wasz-Hockert O, Poisson N, Dumitrescu N, Verron $\mathrm{M}$, Couvet E. A bibliography of the complications of BCG vaccination. A comprehensive list of the world literature since the introduction of BCG up to July 1982, supplemented by over 100 personal communications. Adv Tuberc Res. 1984;21:194-245.

35. Aquilina S, Gatt P, Boffa MJ. Pilomatricoma arising at a BCG vaccination site. Clin Exp Dermatol. 2005;31:296-7.

36. Raaschou-Nielsen W. Psoriasis vaccinalis: report of two cases, one following B.C.G. vaccination and one following vaccination against influenza. Acta Derm Venereol. 1955;35:37-42.

37. Osborne GEN, Mallon E, Mayou SC. Juvenile sarcoidosis after BCG vaccination. J Am Acad Dermatol. 2003;48:S99-102.

38. Miyakura T, Yamamoto T, Tsuboi R. Case of Bowen's disease occurring in an old Bacille Calmette-Guerin vaccination site [letter]. J Dermatol. 2007;34:416-7.

39. Carpentier O, Piette F, Delaporte E. Sweet's syndrome after BCG vaccination [letter]. Acta Derm Venereal. 2002;82:221.

40. Radeff B, Harms M. Acute febrile neutrophilic dermatosis (Sweet's syndrome) following BCG vaccination. Acta Derm Venereol. 1986;66:357-8.

41. Zeng YP, Ma DL. Tufted angioma arising at a site of BCG vaccination. Eur J Dermatol. 2013;23:102-3.

42. Kuniyuki S, Asada M. An ulcerated lesion at the BCG vaccination site during the course of Kawasaki disease. J Am Acad Dermatol. 1997;27:303-4.

43. Lai C-C, Lee P-C, Wang C-C, Hwang B-T, Meng CCL, Tsai M-C. Reaction at the Bacillus Calmette-Guerin inoculation site in patients with Kawasaki disease. Pediatr Neonatol. 2013;54:43-8. 
44. Ghattaura A, Eley KA, Molenaar E, Smith G. A case of extensive ulcerating vasculitis following a BCG vaccination. J Plast Reconstr Aesthet Surg. 2009;62:e286-9.

45. Vanoli M, Gambini D, Scorza R. A case of Churg-Strauss syndrome vasculitis after hepatitis B vaccination. Ann Rheum Dis. 1998;57:256-7.

46. Wolf F, Grezard P, Berard F, Clavel G, Pervot H. Generatlized granulare annulare and hepatitis B vaccination. Eur J Dermatol. 1998;8:435-6.

47. Stavrianeas NG, Katoulis AC, Kanelleas A, Hatziolou E, Georgala S. Papulonodular lichenoid and pseudolymphomatous reaction at the injection site of hepatitis $B$ virus vaccination. Dermatology. 2002;205:166-8.

48. Poulton JK, Kauffman CL, Lutz LL, Sina B. Solitary mastocytoma arising at a hepatitis $B$ vaccination site. Cutis. 1999;63:37-40.

49. Ajithkumar K, Anand U, Pulimood S, Chandi SM, George S, Jacob CK, Thomas PP. Vaccine-induced necrobiotic granuloma. Clin Exp Dermatol. 1998;23:222-4.

50. Miller KD, Gibbs RD, Mulligan MM, Nutman TB, Francis DP. Intradermal hepatitis B virus vaccine. Immunogenicity and side effects in adults. Lancet. 1983;2:1454-6.

51. Cerroni L, Borroni RG, Massone C, Chott A, Keel $\mathrm{H}$. Cutaneous B-cell pseudolymphoma at the site of vaccination. Am J Dermatopathol. 2007;29:538-42.

52. Saywell CA, Wittal RA, Kossard S. Lichenoid reaction to hepatitis $B$ vaccination. Lichenoid reaction to hepatitis B vaccination. Australasian J Dermatol. 1997;38:152-4.

53. Rebora A, Rongioletti F, Drago F, Parodi A. Lichen planus as a side effect of $\mathrm{HBV}$ vaccination. Dermatology. 1999;198:1-2.

54. Kroger A, Vellozzi C, Deming M, Casey CG, Wen $X$, Norton SA. Dermatological lesions near the smallpox vaccination site after scab detachment. Clin Infect Dis. 2008;46:s227-33.

55. Marmelzat WL. Malignant tumors in smallpox vaccination scars: a report of 24 cases. Arch Dermatol. 1968;97:400-6.

56. Zelickson AS. Basal cell epithelioma at site and following smallpox vaccination: report of a case. Arch Dermatol. 1968;98:35-6.

57. Waibel KH, Walsh DS. Smallpox vaccination site complications. Int J Dermatol. 2006;45:684-8.
58. Hendricks WM. Dermatofibroma occurring in a smallpox vaccination scar. J Am Acad Dermatol. 1987;16:146-7.

59. Rubin Z, Hyman AB. Nodules cutaneous with hemorrhage in a smallpox vaccination scar. Arch Dermatol. 1965;92:406-9.

60. Green JJ, Heymann WR. Dermatofibrosarcoma protuberans occurring in a smallpox vaccination scar. J Am Acad Dermatol. 2003;48(5 Suppl):S54-5.

61. Coetzee T. Sarcoma developing in scar. S Afr J Surg. 1964;2:49-54.

62. Archampong EQ, Clark CG. Fibrosarcoma at the site and immediately following small-pox vaccination. Br J Surg. 1970;57:937-8.

63. Mintz L. Recurrent herpos simplex infection at a smallpox vaccination site. JAMA. 1982;247:2704-5.

64. Waibel KH, Walsh DS. Smallpox vaccination site reactions: two cases of exaggerated scarring and a brief review. Int J Dermatol. 2006;45:764-5.

65. Musgrave RM. The pitfall of surgical excision of vaccination scars in the deltoid area. Plast Reconstr Surg. 1973;51:198-9.

66. Wharton M, Strikas RA, Harpaz R, Rotz LD, Schwartz B, Casey CG, Pearson ML, Anderson LJ, Advisory Committee on Immunization Practices, Healthcare Infection Control Practices Advisory Committee. Recommendations for using smallpox vaccine in a pre-event vaccinations program. Supplemental recommendations of the Advisory Committee on Immunization Practices (ACIP) and the Healthcare Infection Control Practices Advisory Committee (HICPAC). MMWR Recomm Rep. 2003;52(RR-7):1-16.

67. Waddington E, Bray PT, Evans AD, Richards ID. Cautaneous complications of mass vaccination against smallpox in South Wales 1962. Trans St Johns Hosp Dermatol. 1964;50:22-42.

68. Gordon H. Complications of smallpox vaccination: basal cell carcinoma, keloids, and acute bullous reactions. Cutis. 1974;13:444-7.

69. Haider S. Keratoacanthoma in a smallpox vaccination site. Br J Dermatol. 1974;90:689-90.

70. Lupton GP. Discoid lupus erythematosus occurring in a smallpox vaccination scar [letter]. J Am Acad Dermatol. 1987;17:688-90.

71. Onwukwe MF. Cutaneous complications of smallpox vaccination scars. Int $\mathrm{J}$ Dermatol. 1973;12:290-4. 
72. Slater DN, Parsons MA, Fussey IV. Malignant fibrous histiocytoma arising in a smallpox vaccination scar. Br J Dermatol. 1981;105:215-7.

73. Reed WB, Wilson-Jones E. Malignant tumors as a late complication of vaccination. Arch Dermatol. 1968;98:132-5.

74. Pujol RM, Monmany J, Bague S, Alomar A. Graves' disease presenting as localized myxoedematous infiltration in a smallpox vaccination scar. Clin Exp Dermatol. 2000;25:132-4.

75. Porter D, Earle J. Jadassohn tumour arising at smallpox vaccination site. $\mathrm{Br} \mathrm{J}$ Dermatol. 1972;86:177-9.

76. Helman J. Pigmented vaccination scars. S Afr Med J. 1978;53:430.

77. Kumar LR, Goyal BG. Pigmentary hairy scar following smallpox vaccination. Indian J Pediatr. 1968;35:283-4.

78. Cono J, Casey CG, Bell DM. Smallpox vaccination and adverse reactions. Guidance for clinicians. MMWR. 2003;52(RR04):1-28.

79. Gunawardena DA, Gunawardena KA, Ratnayaka RM, Vasanthanathan NS. The clinical spectrum of Sweet's syndrome (acute febrile neutrophilic dermatosis) - a report of eighteen cases. $\mathrm{Br} J$ Dermatol. 1975;92:367-73.

80. Stringfellow HF, Howat AJ. Postimmunization (vaccination) injection-site reactions. Am J Surg Pathol. 1994;18:1179-80.

81. Baykal C, Ozkaya-Bayazit E, Kaymaz R. Granuloma annulare possibly triggered by antitetanus vaccination. J Eur Acad Dermatol Venereol. 2002;16:516-8.

82. Dixit R, Dixit K, Patil CB, Pawar KS. Injection site abscess due to Mycobacterium tuberculosis following DPT vaccination. Indian J Tuberc. 2014;61:246-9.

83. Miliauskas JR, Mukherjee T, Dixon B. Postimmunization (vaccination) injection-site reactions. A report of four cases and review of the literature. Am J Surg Pathol. 1993;17: 516-24.

84. Borghans JGA, Stanford JL. Mycobacterium chelonae in abscess after infection of DPT polio vaccine. Am Rev Respir Dis. 1973;107:1-8.

85. Beveridge MG, Polcari IC, Burns JL, Adler A, Hendrickson B, Stein SL. Local vaccine site reactions and contact allergy to aluminum. Pediatric Dermatol. 2012;29:68-72.
86. Morman MR, Lin R-Y, Petrozzi JW. Dermatofibrosarcoma protuberans arising in a site of multiple immunizations. Arch Dermatol. 1978;115:1453.

87. Hali F, Sbai M, Benchikhi H, Ouakadi A, Zamiati S. Sweet's syndrome after H1N1 influenza vaccination. Ann Dermatol Venereol. 2002;137:740-1.

88. Javanovic M, Paljacki M, Vujanovic L, Duran V. Acute febrile neutrophilic dermatosis (Sweet's syndrome) after influenza vaccination [letter]. J Am Acad Dermatol. 2005;52:367-9.

89. Tan AW, Tan H-H, Lim PL. Bullous Sweet's syndrome following influenza vaccination in a HIV-infected patient. J Am Acad Dermatol. 2006;45:1254-5.

90. Yazdanpanah MJ, Noorbakhsh SR, Kalantari MR, Maleki M, Kiafar B. Dermatofibroma protuberans occurring in the site of prior leishmanization. Int J Dermatol. 2006;45:1476-7.

91. Macaladad N, Marcano T, Guzman M, Moya J, Jurado F, Thompson M, Meechan C, Li D, Schlienger K, Chan I, Sadoff J, Schodel F, Silber JL. Safety and immunogenicity of a zoster vaccine in varicella-zoster virus seronegative and low-seropositive healthy adults. Vaccine. 2007;25:2139-44.

92. Pseudolymphomatous reaction to varicella zoster virus vaccination: role of viral in situ hybridization. J Cutan Pathol. 2010;37:1098-102.

93. Gershon AA, Steinberg SP, Gelb L. Live attenuated varicella vaccine use in immunocompromised children and adults. Peditrics. 1986;78(4Pt2):757-62.

94. Elgart GW, Hanly A, Busso M, Spener JM. Bednar tumor (pigmented dermatofibrosarcoma protuberans) occurring in a site of prior immunization: immunochemical fingdings and therapy. J Am Acad Dermatol. 1999;40:315-7.

95. Taylor HB, Helwig EB. Dermatofibrosarcoma protuberans: a study of 115 cases. Cancer. 1962;15:717-25.

96. Chen TM, Nguyen TH, Cohen JL. Adult with a red plaque at the site of a childhood vaccination scar [photo quiz]. Am Fam Physician. 2009;79:995-6.

97. Anderton RL, Abele DC. Lichen sclerosus et atrophicus in a vaccination site [letter]. Arch Dermatol. 1976;112:1787.

98. Huynh TN, Jackson JD, Brodell RT. Tattoo and vaccination sites: possible nests for opportunistic infections, tumors, and dysimmune reactions. Clin Dermatol. 2014;32:678-84. 
99. Ruocco V, Brunetti G, Puca RV, Ruocco E. The immunocompromised district: a unifying concept for lymphoedematous, herpes-infected and otherwise damaged sites. J Eur Acad Dermatol Venereol. 2009;23:1364-73.

100. Ruocco V, Ruocco E, Piccolo V, Brunetti G, Guerrera LP, Wolf R. The immunocompromised district in dermatology: a unifying pathogenic view of the regional immune dysregulation. Clin Dermatol. 2014;32:569-76.
101. Schiavo AL, Ruocco E, Gambardella A, O'Leary RE, Gee S. Granulomatous dysimmune reactions (sarcoidosis, granuloma annulare, and others) on differently injured skin areas. Clin Dermatol. 2014;32:646-53.

102. Piccolo V, Baroni A, Russo T, Schwartz RA. Rucco's immunocompromised cutaneous district. Int J Dermatol. 2016;55:135-41. 